\title{
Genetic variation and structure of Juniperus chinensis L. (Cupressaceae) in Korea
}

\author{
Eun-Hye Kim ${ }^{1,2}$, Jae-Kwon Shin ${ }^{3}$, Keum-Seon Jeong ${ }^{4}$, Chang-Seok Lee ${ }^{1}$ and Jae-Min Chung ${ }^{3^{*}}$ (D)
}

\begin{abstract}
Background: Juniperus chinensis L. populations are distributed locally on several areas including coastal cliffs which are difficult to access in the central eastern Korea. Wild populations inhabit relatively barren environments such as rocky areas and cliffs, which are very sensitive to even minor environmental disturbances including artificial interventions and natural disturbances, and thus demonstrate great fluctuations in the population size and density. This study aims to analyze the genetic diversity, differentiation, and genetic structure of each population in order to provide useful data required to establish a substantial conservation strategy of $J$. chinensis.

Results: The genetic diversity of $J$. chinensis at the population level $(P=78.7 \%, h=0.282, S .1 .=0.420)$ was somewhat higher compared with those measured in the same genus, Juniperus. The genetic differentiation degree among nine populations established naturally in central eastern Korea was $11.50 \%$ and that among sub-populations within the same area was $5.52 \%$. On the other hand, genetic variation of individuals within the populations was $82.93 \%$. But frequency of the main allele was different among loci. In particular, fixation of allele frequency and occurrence of rare allele in the highly isolated population suggest a likelihood that genetic drift would occur in populations of this plant. As the result of analysis on the genetic structure of nine populations, nearby populations and isolated populations tended to form separate clusters from each other as the hypothetical number of clusters $(K)$ increase.

Conclusions: This result implies that if the population size of $J$. chinensis is reduced due to environmental change and artificial and/or natural disturbances in the future, it could affect negatively on the genetic diversity of the plant species. In order to maintain and conserve genetic diversity of J. chinensis, ecological network, which can help genetic exchange among the local populations, should be prepared, and conservation strategies in situ as well as ex situ are also required with continuous monitoring.
\end{abstract}

Keywords: Juniperus chinensis, Inter-simple-sequence repeat (ISSR), Genetic diversity, Structure, Conservation

\section{Background}

Plant population usually shows high genetic variability. The mating system, life form, population structure, population size, and fecundity have all been cited as determinants of both the overall genetic variability within plant species and the distribution of this variability within and between populations (Hamrick and Godt 1990). Levels of genetic diversity within and among populations have important consequences for the evolutionary trajectories of species and for the function and composition of ecological communities (Hughes et al. 2008). Genetic diversity influences functional trait variation, recovery of populations

\footnotetext{
* Correspondence: rhuso@korea.kr

${ }^{3}$ Division of Forest Resource Conservation, Korea National Arboretum,

Pocheon, Gyeonggi-do 11886, Korea

Full list of author information is available at the end of the article
}

following disturbance, species interactions, community structure, and nutrient and energy fluxes (Hughes et al. 2008; Bell and Gonzalez 2009). Consequently, understanding how genetic diversity is distributed in time and space is critical for managing biodiversity over broad spatial scales (e.g., responses to climate change) within biologically realistic time frames (i.e., decadal and longer) and helping to guide investments into on-ground actions (e.g., restoration).

Both adaptive and neutral evolutionary processes shape the distribution of genetic variation within species. While knowledge on the genetic variation underlying past adaptation and potentially available for future adaptation is an ideal for conservation and restoration ecology, assessing this variation is both time-consuming and resource intensive (e.g., common garden or transplant

(c) The Author(s). 2018 Open Access This article is distributed under the terms of the Creative Commons Attribution 4.0 International License (http://creativecommons.org/licenses/by/4.0/), which permits unrestricted use, distribution, and 
studies). Such assessments often require large-scale and often long-term quantitative genetic studies, with the validation of associations between functional traits and fitness being challenging (Rockman 2012). Consequently, for the majority of species of interest in conservation, we must continue to largely rely on putatively neutral genetic variation to link molecular variants with functional traits. In plants, neutral genetic variation is influenced by a range of life-history and geographic and demographic attributes, such as growth form, range size, and abundance (Hamrick and Godt 1996). Understanding associations between these species attributes and the level and structuring of neutral genetic diversity can help build generalizations to guide conservation and restoration decisions, especially for plant species where little or no information exists. These generalizations would be useful for developing guidelines for the management of small populations of threatened species (Frankham 2015).

Habitat fragmentation is a significant threat to the maintenance of biodiversity in many terrestrial ecosystems (Gonzalez et al. 2009). Many studies have investigated the effects of fragmentation on the genetic diversity and population structure of plant species (Nybom 2004). In general, fragmentation is expected to reduce genetic diversity and to increase interpopulation genetic divergence by restricting gene flow among fragmented populations, increasing inbreeding, and increasing random genetic drift within populations. However, habitat fragmentation does not always lead to reduced genetic variation (Young et al. 1996). In some cases, the genetic diversity of a fragmented population can be higher than that of a continuously distributed population (Llorens et al. 2004). This is because the effects of habitat fragmentation on genetic diversity and population structure can be affected by other factors, such as population size, gene flow, and the time scale of fragmentation (Jeong et al. 2010).

Fragmented distributions of plant populations are caused not only by human activity but also by natural factors, such as long-term, large-scale climate oscillations, topographical changes, the isolation of suitable habitats, or other ecological changes. Studies of the genetic diversity of naturally fragmented populations may not only reveal the ecological consequences of population fragmentation over long periods of time but also provide a frame of reference for predicting the consequences of habitat fragmentation by human activities. Genetic analyses of naturally fragmented populations have been conducted in several studies (Hou and Lou 2011).

Juniperus chinensis belongs to family Cupressaceae and is distributed throughout the warm temperate and temperate climate zones in the northern hemisphere including Korea, China, Mongolia, Japan, Myanmar, and Russia (IUCN 1998; Farjon 2005, 2008). It is a tall evergreen shrub with a unique scent, which is used as air freshener, furniture wood, ornamental plant, and so on. The extract of $J$. chinensis contains $\alpha$-piene, limonene, cedrol, widdrol, and cedrene, and thereby is considered as an important plant resource with a high potential value in developing new anticancer drugs or drugs against various diseases (Adams 2011; Jo 2012). J. chinensis is categorized as a least-concern species in 1998 on the IUCN Red List although they experience overcutting and destruction of its habitats. J. chinensis populations are distributed locally on the coastal cliffs of Ulleung Island and several areas in Gangwon-do and Gyungsangbuk-do located on the central eastern Korea, which are difficult to access (Lee 2005; Ulleung County The Office 2007).

Wild populations of $J$. chinensis inhabit relatively barren environments such as rocky areas and cliffs, which are very sensitive to even minor environmental disturbances including artificial interventions and natural disasters, and thus demonstrate great fluctuations in the population size and density. Indeed, damaged habitats of woody plants require a much longer period for recovering original vegetation than herbaceous plants. Therefore, they are prone to be isolated genetically. Consequently, as the effective size of population decrease and alleles lose, genetic drift and bottleneck phenomenon increase (Hartl and Clark 1997). Moreover, imbalance in the sex ratio of dioecious plant species such as $J$. chinensis not only reduces the population size but also causes a bottleneck phenomenon (Murphy 1990). In addition, owing to the pressure of inbreeding, various genes are lost and abnormal offspring are reproduced. This, in turn, causes a decrease in the adaptability of individuals, and eventually the possibility of extinction increases.

As damage to natural ecosystem continues to increase, the conservation of biodiversity is gaining more concern. Since the Convention on Biological Diversity was established at the Earth Summit in Rio de Janeiro, Brazil, in 1992, conservation of biodiversity and sustainable use of its components have been adopted domestically and internationally, and each country participate in various international cooperation and legal means for the conservation of biodiversity. Methods for the conservation of genetic resources of biological species are categorized into in situ conservation and ex situ conservation. These conservation methods are not only to prevent the extinction of species but also to conserve habitats or create alternative habitats. They serve the function of a gene bank by restoring habitats, securing an abundance of genetic variation and diversity, and maintaining populations of effective size for a long-term supply of seeds for the next generation. Therefore, it is required to establish an appropriate conservation plan by securing genetic data on the objective species for efficient conservation and management of genetic resources. In this respect, analysis on the gene diversity of local populations of a 
species that conservation is required can play a key role in providing information to systematically establish conservation strategies for comprehensive conservation and management of species (Hughes et al. 2008).

This study aims to analyze the genetic diversity, differentiation, and genetic structure of each population in order to provide useful data required to establish a substantial conservation strategy of $J$. chinensis, which is categorized as a least concern by IUCN.

\section{Methods}

DNA extraction and polymerase chain reaction amplification For the genetic analysis, 196 individuals of J. chinensis were collected from nine populations from 2010 to 2013. We collected from 12 to 49 samples for each population based on the population size (Table 1 and Fig. 1). All individuals sampled within each population were separated by at least $2 \mathrm{~m}$ to avoid collecting the same clone.

Total genomic DNA was extracted from fresh and frozen leaves using the Dneasy Plant Mini Kit (Qiagen) following the manufacturer's manual. The sixty ISSR primers (UBC biotechnology laboratory primers) were screened to produce reliable and reproducible bands for data scoring, and six primers were selected for evaluating genetic diversity (Table 2). PCR amplification was conducted using selected primers in a total reaction volume of $20 \mu \mathrm{l}$ containing $10 \mathrm{ng}$ of total DNA, each primer at $300 \mathrm{nM}, 1 \times$ PCR reaction buffer, $0.2 \mathrm{mM}$ dNTPs, $0.00025 \%$ BSA, and 0.8 unit Taq polymerase (Genecreft, Biothem). Polymerase chain reaction (PCR) conditions were an initial denaturation of $94{ }^{\circ} \mathrm{C}$ for $2 \mathrm{~min}, 35$ cycles of $94{ }^{\circ} \mathrm{C}$ denaturation for $45 \mathrm{~s}, 50-52{ }^{\circ} \mathrm{C}$ annealing for $45 \mathrm{~s}$, extension of $72{ }^{\circ} \mathrm{C}$ for $1 \mathrm{~m} 30 \mathrm{~s}$, and final extension at $72{ }^{\circ} \mathrm{C}$ for $10 \mathrm{~min}$. The PCR products were subjected to gel electrophoresis for $2 \mathrm{~h}$ in a $1.5 \%$ agarose gel $(w / v)$ using a $1 \mathrm{xTBE}$ buffer ( $\mathrm{pH}$ 8.0). Following the electrophoresis, the gel was stained with ethidium bromide and was visualized under a UV transilluminator using the gel documentation system.

\section{Genetic analysis of data}

The data were scored as 1 for presence (dominant type) or 0 for absence (recessive type) of a DNA band in each locus and then used for further analyses. All the genetic analyses were carried out based on the presence frequency of the aforementioned marker bands. The Popgen program (Yeh et al. 1999) was used to analyze the percentage of polymorphic bands $(P)$, the mean number of alleles per locus $(A)$, the effective number of alleles per locus (Ae), and Shannon and Weaver (1949) information index (S.I.). For comparison with other studies, Nei's (1973) gene diversity $(h)$ was calculated by estimating the frequency of the recessive alleles under the assumption of the H-W equilibrium. Gene flow (expected as $\mathrm{Nm}$ ) was estimated from $G_{\mathrm{ST}}$ value $\left[\left(\mathrm{Nm}=0.5\left(1-G_{\mathrm{ST}} / G_{\mathrm{ST}}\right) ; \mathrm{McDermott}\right.\right.$ and McDonald 1993)]. A dendrogram was constructed using the unweighted pair group method average (UPGMA) clustering procedure based on Nei's genetic distance (1978). The molecular variance (AMOVA) was analyzed using Arlequin ver. 3.11 (Excoffier et al. 2005) to determine the degree of the genetic diversity distribution within and among the populations. To examine the correlation between genetic differentiation and geographic distances among populations, Mantel tests (Legendre and Legendre 1998) were conducted using the computer program IBD (isolation by distance) ver. 1.52 (Bohonak 2002). In addition, STRUCTURE ver.2.3.3 software (Falush et al. 2007) was used to identify distinct sub-populations and to determine fractions of the haplotype for each strain that belong to each sub-population. The simulations were run 10 times for each $K$ value (1-10), for 100,000 iterations, after a burn-in period of 50,000, using the admixture model and under the assumption of correlated allele frequencies (Falush et al. 2003; Evanno et al. 2005). And values of the $\log$ likelihood of the data $\operatorname{LnP}(D)$ as a function of the number of clusters $(K)$ resulting from the simulation using the STRUCTURE method, and $\Delta K$ based

Table 1 Localities, sample size (Ns), and total number of individuals in population ( $N$ ) of $J$. chinensis examined in this study

\begin{tabular}{|c|c|c|c|c|c|}
\hline Locality & Population abbreviation & GPS & Habitat type & Ns & $N$ \\
\hline Samcheok-si, Geundeok-myeon, Korea & SC1 & $\mathrm{N} 37^{\circ} 19^{\prime}, \mathrm{E} 129^{\circ} 16^{\prime}$ & Coastal cliff & 21 & 43 \\
\hline Samcheok-si, Wondeok-eup A, Korea & SC2 & $\mathrm{N} 37^{\circ} 16^{\prime}, \mathrm{E} 129^{\circ} 19^{\prime}$ & Coastal cliff and sea-stack & 12 & 35 \\
\hline Samcheok-si, Wondeok-eup B, Korea & SC3 & $\mathrm{N} 37^{\circ} 11^{\prime}, \mathrm{E} 129^{\circ} 20^{\prime}$ & Mid slope and coastal deposit & 24 & 31 \\
\hline Donghae-si, Chuam-dong, Korea & DB & $\mathrm{N} 37^{\circ} 28^{\prime}, \mathrm{E} 129^{\circ} 09^{\prime}$ & Coastal cliff and coastal deposit & 25 & 117 \\
\hline Gangneung-si, Gangdong-myeon, Korea & KS & $\mathrm{N} 37^{\circ} 39^{\prime}, \mathrm{E} 129^{\circ} 04^{\prime}$ & Coastal cliff & 20 & $>300$ \\
\hline Ulleung-gun, Korea & UL & $\mathrm{N} 37^{\circ} 27^{\prime}, \mathrm{E} 130^{\circ} 52^{\prime}$ & Coastal cliff & 49 & $>1000$ \\
\hline Yeongdeok-gun, Chuksan-myeon, Korea & YD & $\mathrm{N} 36^{\circ} 28^{\prime}, \mathrm{E} 129^{\circ} 26^{\prime}$ & Mountain foot & 19 & 25 \\
\hline Uljin-gun, Giseong-myeon, Korea & US & N36 $51^{\prime}, E 129^{\circ} 25^{\prime}$ & Coastal cliff & 19 & 42 \\
\hline Jeongseon-gun sindong-eup, Korea & JS & $\mathrm{N} 37^{\circ} 19^{\prime}, \mathrm{E} 128^{\circ} 37^{\prime}$ & Riverine cliff & 16 & $>120$ \\
\hline
\end{tabular}




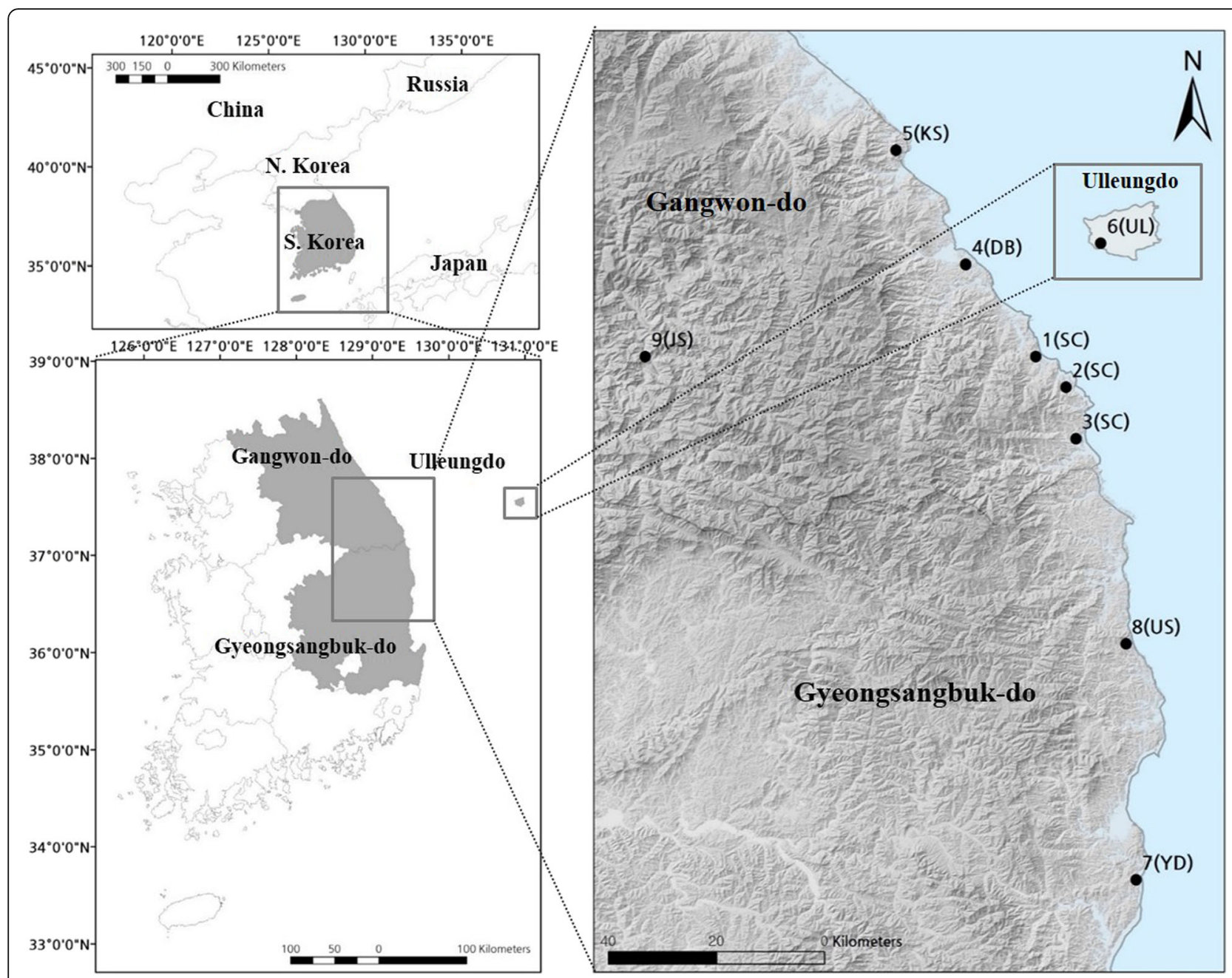

Fig. 1 Location of nine sampling sites of $J$. chinensis in Korea (1, SC1; 2, SC2; 3, SC3; 4, DB; 5, KS; 6, UL; 7, YD; 8, US; 9, JS)

on the rate of change of $\ln \operatorname{LnP}(D)$ between successive $K$ values were conducted.

\section{Results}

\section{Genetic diversity}

The total number of 47 loci was observed of six primers; polymorphic bands were observed in 46 of the loci. In the analysis of allele frequency at each locus, 14 loci had

Table 2 ISSR primers analyzed for J. chinensis examined in this study and the sequences and annealing temperatures for polymerase chain reaction (PCR)

\begin{tabular}{|c|c|c|c|c|c|c|c|}
\hline Primer & Annealing temp. $\left({ }^{\circ} \mathrm{C}\right)$ & Seque & ence & & & & \\
\hline UBC\#809 & 52 & AGA & GAG & AGA & GAG & AGA & GG \\
\hline UBC\#811 & 52 & GAG & AGA & GAG & AGA & GAG & $A C$ \\
\hline UBC\#813 & 50 & CTC & TCT & CTC & TCT & CTC & $\pi$ \\
\hline UBC\#818 & 52 & CAC & ACA & CAC & ACA & CAC & $A G$ \\
\hline UBC\#822 & 50 & $\mathrm{TCT}$ & $\mathrm{CTC}$ & $\mathrm{TCT}$ & CTC & TCT & CA \\
\hline UBC\#834 & 52 & AGA & GAG & AGA & GAG & AGA & GYT \\
\hline
\end{tabular}

common major alleles, and in the other 32 loci, different major alleles were observed according to the population tested. As the result of examination on band, the phenotype that was commonly observed at all loci was analyzed and a unique allele was observed only in the UL population.

The proportion of the polymorphous loci $(P)$ in the $J$. chinensis populations confirmed in this study was as follows: the UL population had the highest of all recording (93.6\%), the KS population had the lowest (61.7\%), and the population average was $78.7 \%$. The observed alleles (A) were the most frequent in the $\mathrm{DB}$, UL, and US populations as 1.9 alleles. The KS population had the least number of observed alleles (1.6), and the population average was 1.8. The effective number of alleles (Ae) per locus, which indicates the evenness of gene frequency in each locus, was the lowest as 1.4 in the KS and YD populations. The other populations maintained similar values to each other as the population average was 1.5. The gene diversity index $(h)$ and the Shannon index (S.I.) were the 
highest in the DB population as 0.314 and 0.468 , respectively, and were the lowest in the KS population as 0.227 and 0.336 , respectively. The population average values for $h$ and SI were 0.282 and 0.420 , respectively (Table 3 ).

\section{Genetic differentiation and structure}

In order to investigate the degree of genetic differentiation of $J$. chinensis, a hierarchical analysis was performed using analysis of molecular variance (AMOVA) (Table 4). The degree of differentiation in the three populations (SC1, SC2, SC3) located closely within the same site was $5.52 \%$, and the level of genetic differences between the populations within the site was not large. The UL population; four populations of $\mathrm{DB}, \mathrm{KS}, \mathrm{YD}$, and US; and JS population were located on island, coastal area, and inland, respectively. The differentiation degree among these populations was $11.50 \%$, and the genetic variation within the populations was $82.98 \%$ (Table 4 ). The degree of differentiation of SC1 and SC2, which are adjacent to each other, was very low as $0.45 \%$. Almost no genetic variation was observed between these two populations; however, the genetic variation of SC2 and JS was very high as is recorded at $28.35 \%$ (Table 5). The gene flow between the populations was calculated as 2.05. A Mantel test was performed with the differentiation values of each population and the log values of the linear distance between them. The $P$ value was a positive $0.421(p<0.05)$, and the differentiation exhibited an increasing tendency as the distance between the populations become farther.

A cluster analysis was performed using the genetic distance between the populations. The SC1 and DB populations clustered first, and SC2, US, and SC3 formed another group. The UL and KS populations clustered

Table 3 Genetic variability in nine populations of J. chinensis estimated by 47 ISSR loci

\begin{tabular}{|c|c|c|c|c|c|c|c|c|}
\hline \multirow[t]{2}{*}{ Population } & \multirow[t]{2}{*}{$N$} & \multirow[t]{2}{*}{ P.95 (\%) } & \multirow[t]{2}{*}{$A$} & \multirow[t]{2}{*}{$\mathrm{Ae} / \mathrm{L}$} & \multirow[t]{2}{*}{$h$} & \multirow[t]{2}{*}{ S.I } & \multirow{2}{*}{$\frac{\text { Ratio }}{\mathrm{M} / \mathrm{F}}$} & \multirow[t]{2}{*}{$\mathrm{Ne} / \mathrm{N}$} \\
\hline & & & & & & & & \\
\hline $\mathrm{SC} 1$ & 21 & 83.0 & 1.8 & 1.5 & 0.294 & 0.439 & 1.18 & 0.99 \\
\hline SC2 & 12 & 76.6 & 1.8 & 1.5 & 0.293 & 0.431 & 0.73 & 0.98 \\
\hline $\mathrm{SC} 3$ & 24 & 83.0 & 1.8 & 1.5 & 0.281 & 0.422 & 1.67 & 0.94 \\
\hline DB & 25 & 87.2 & 1.9 & 1.5 & 0.314 & 0.468 & 0.58 & 0.93 \\
\hline KS & 20 & 61.7 & 1.6 & 1.4 & 0.227 & 0.336 & 0.47 & 0.87 \\
\hline UL & 49 & 93.6 & 1.9 & 1.5 & 0.307 & 0.464 & 1.47 & 0.96 \\
\hline YD & 19 & 66.0 & 1.7 & 1.4 & 0.252 & 0.373 & 1.00 & 1.00 \\
\hline US & 19 & 87.2 & 1.9 & 1.5 & 0.313 & 0.465 & 0.90 & 1.00 \\
\hline JS & 16 & 70.2 & 1.7 & 1.5 & 0.258 & 0.381 & 1.14 & 1.00 \\
\hline Mean & 22.8 & 78.7 & 1.8 & 1.5 & 0.282 & 0.420 & 1.02 & 0.96 \\
\hline
\end{tabular}

$N$, number of individuals analyzed; $P_{.95}$, percent of polymorphic bands; $A$, number of alleles per locus; Ae/L, effective alleles per locus; $h$, Nei's gene diversity; $S . I$, Shannon and Weaver information index; $M / F$, the ratio of females over the number of males; $\mathrm{Ne} / \mathrm{N}$, effective of individual per total individuals
Table 4 Analysis of molecular variance (AMOVA) at the ISSR loci in total nine populations within three populations of the SC site, in J. chinensis

\begin{tabular}{lccll}
\hline Source of variation & d.f & $\begin{array}{l}\text { Sum of } \\
\text { squares }\end{array}$ & $\begin{array}{l}\text { Variance } \\
\text { components }\end{array}$ & $\begin{array}{l}\text { Percentage } \\
\text { of variation }\end{array}$ \\
\hline Among region & 6 & 265.17 & 0.99 & 11.50 \\
$\begin{array}{l}\text { Among populations } \\
\text { within area }\end{array}$ & 2 & 31.68 & 0.48 & 5.52 \\
Individual & 187 & 1335.12 & 7.14 & 82.98 \\
Total & 195 & 1631.97 & 8.61 & 100 \\
\hline
\end{tabular}

together to form a group, while YD distributed in the southernmost longitude and JS in the inland were clustered together to form a separate group (Fig. 2). The $\operatorname{LnP}(D)$ of the genetic community structure continue to increased up to $K=7$, a virtual cluster number, and since then gradually decreased. The $\Delta K$ value calculated with $\operatorname{LnP}(D)$ was the greatest when $K$ is 2 and gradually decreased in the latter section (Figs. 3 and 4). When $K=2$, the membership coefficient increased from 0.609 to 0.731, and SC1, SC2, SC3, DB, and US populations formed cluster 1. KS, UL, YD, and JS membership coefficient increased from 0.822 to 0.941 and belonged to cluster 2, which formed individual clusters (Figs. 3 and 4).

\section{Discussion}

The genetic diversity of the $J$. chinensis nine populations $(h=0.282$, S.I. $=0.420)$ was quite lower than that of the compared with those measured in the same genus $J$. chinensis var. sargentii (S.I. $=0.463$, Choi et al. 2004) but was higher than that of $J$. phoenicea $(h=0.130$, Meloni et al. 2006) and J. thurifera ( $h=0.141$, Terrab et al. 2008). It was also higher than that measured for gymnosperms $($ S.I. $=0.386)$ (Nybom 2004). The level of genetic diversity in a population is closely related to the breeding

Table 5 Correlation coefficients between all the combinations of between populations geographic range ( $\mathrm{km}$; below) and genetic differentiation $\left(\Phi_{\text {ST; }}\right.$ top) parameters

\begin{tabular}{|c|c|c|c|c|c|c|c|c|c|}
\hline \multicolumn{10}{|c|}{ Genetic differentiation $\left(\Phi_{S T}\right)$} \\
\hline & \multicolumn{3}{|c|}{$\begin{array}{l}\text { Populations } \\
\text { within region }\end{array}$} & \multicolumn{6}{|c|}{ Populations of region } \\
\hline & $\mathrm{SC} 1$ & $\mathrm{SC2}$ & $\mathrm{SC3}$ & $\mathrm{DB}$ & KS & UL & YD & US & JS \\
\hline SC1 & $* * *$ & 0.45 & 2.06 & 10.17 & 17.41 & 15.80 & 27.27 & 5.95 & 28.80 \\
\hline SC2 & 13 & $* * *$ & 3.00 & 7.92 & 19.31 & 16.23 & 27.85 & 7.39 & 28.35 \\
\hline $\mathrm{SC} 3$ & 7 & 8 & $* * *$ & 5.35 & 18.15 & 14.96 & 26.82 & 3.75 & 25.59 \\
\hline DB & 20 & 32 & 25 & $* * *$ & 12.24 & 17.33 & 26.94 & 9.54 & 26.22 \\
\hline KS & 43 & 60 & 74 & 66 & $* * *$ & 8.98 & 25.77 & 18.64 & 24.02 \\
\hline UL & 146 & 141 & 137 & 135 & 174 & $* * *$ & 18.70 & 14.42 & 15.61 \\
\hline YD & 118 & 97 & 88 & 95 & 154 & 176 & $* * *$ & 25.95 & 16.07 \\
\hline US & 56 & 36 & 23 & 32 & 96 & 139 & 64 & $* * *$ & 20.62 \\
\hline JS & 47 & 53 & 63 & 60 & 46 & 193 & 124 & 78 & $* * *$ \\
\hline
\end{tabular}




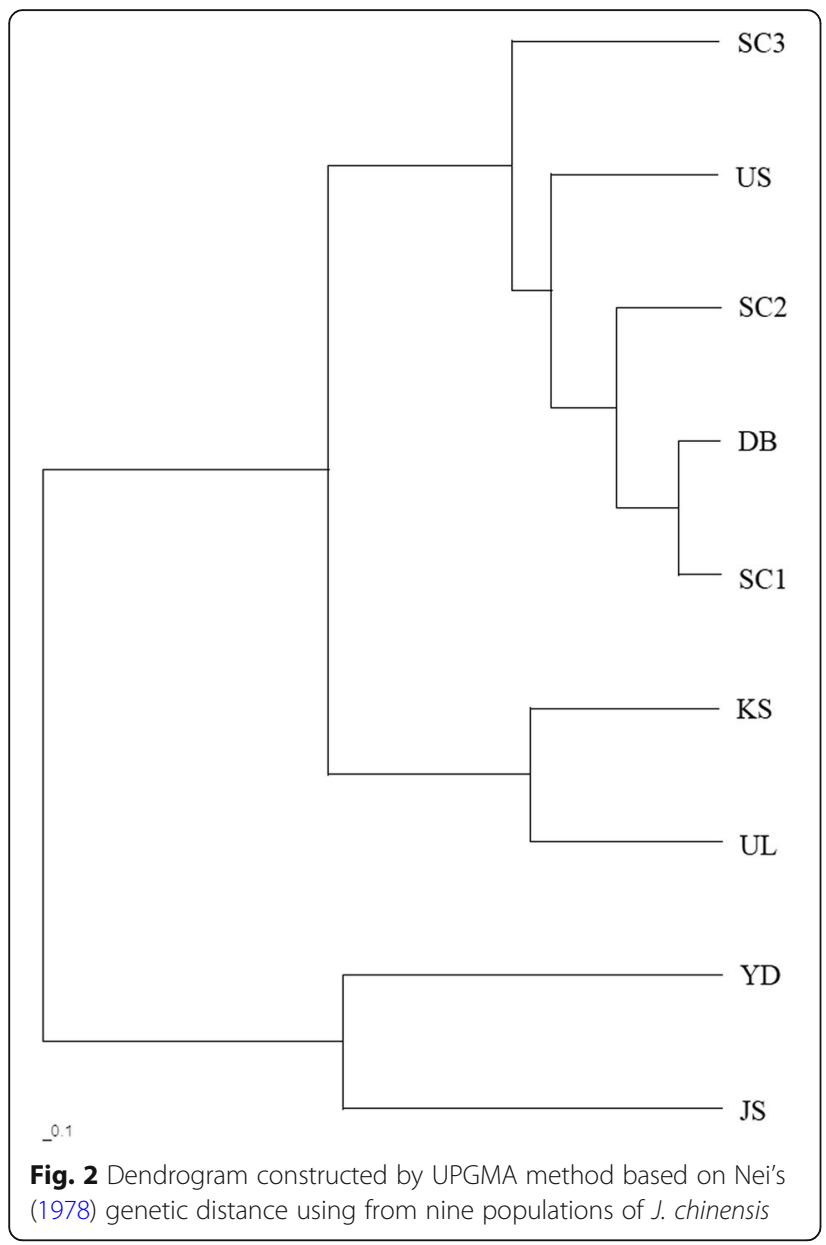

characteristics of the species, and in general, allogamous species tend to exhibit high genetic diversity. J. chinensis is known in a dioecious plant that avoids self-fertilization (Lewis 1942; Thomson and Barrett 1981).

In a study of the formation of sex ratios in J. chinensis (Shin et al. 2015), some populations demonstrated a relatively high infertility even though the number of females in the population was sufficient. This result suggests the possibility of a bottleneck phenomenon following a decrease of the population size. SC1, SC2, $\mathrm{DB}, \mathrm{UL}$, and US populations in this study have higher genetic diversity than the average of all the populations, as is demonstrated by the females and males with a rate minimum of 0.93 to 1.00 , or a rate close to $1: 1$ (Table 3 ). The DB population showed a sex ratio of 0.93 despite its high genetic diversity, suggesting that a bottleneck is likely to occur frequently owing to a decrease in its population size. The conditions for 1:1 sex ratio are not influenced significantly if the population size becomes bigger. On the contrary, if the population size is small and if the sex ratio is even, the population bears a higher possibility of dying out eventually due to the limited number of breeding opportunities (Lienert and Fischer 2003). The KS population had the lowest genetic diversity and sex ratio. Further study is required to clarify the relationships between genetic diversity, population size, and sex ratio. The high level of biodiversity appears to be the result of an accumulation of genetic variation through a repeated overlap of different generations over a long period of time, which is reasonable for a perennial woody plant such as J. chinensis. The habitat of $J$. chinensis populations is usually located on the cliffs, which makes it hard to obtain water and further increases possibility of isolation. In particular, the geographical distribution of habitats takes the form of a small population located on the outskirts of a coast. This state easily leads the J. chinensis populations to ecological isolation and will have a negative effect on the sustainability of the populations in genetic terms due to the extreme pressure for selection. A measure for habitat conservation is required for KS and YD populations inhabiting the coastal areas, as the habitats continue to be damaged and reduced by artificial

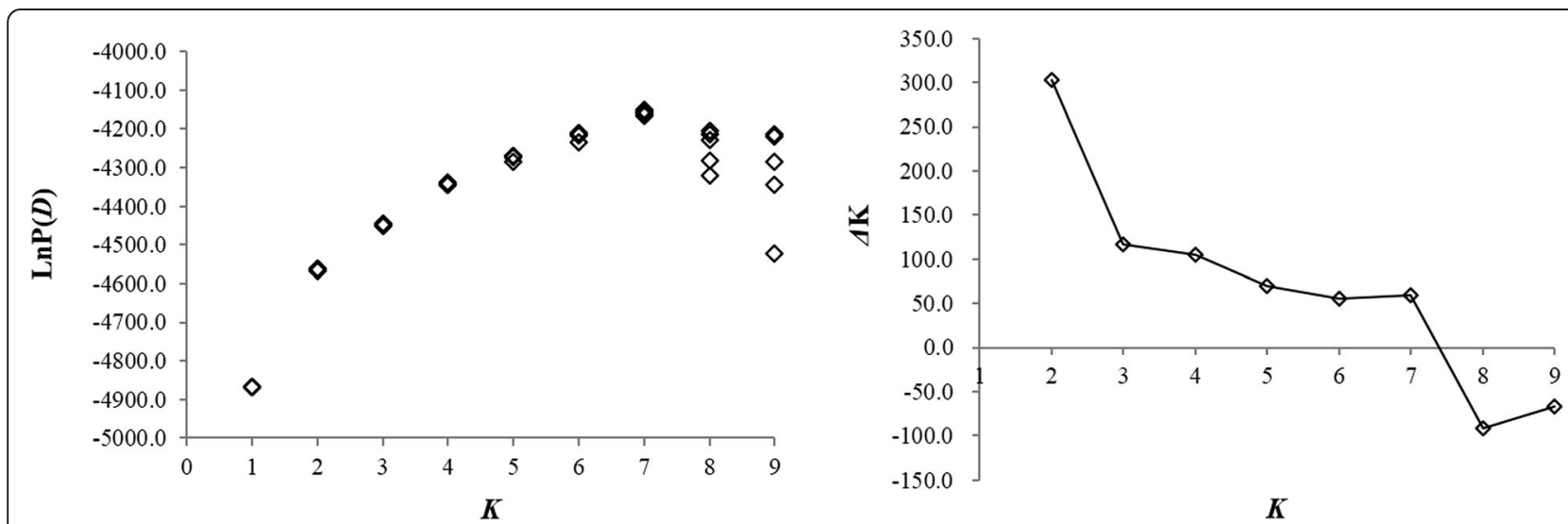

Fig. 3 Values of the log likelihood of the data $\operatorname{LnP}(D)$ as a function of the number of clusters $(K$ ) resulting from the simulation using the STRUCTURE method, and $\Delta K$ based on the rate of change of $\ln \operatorname{Ln} P(D)$ between successive $K$ values of $J$. chinensis 


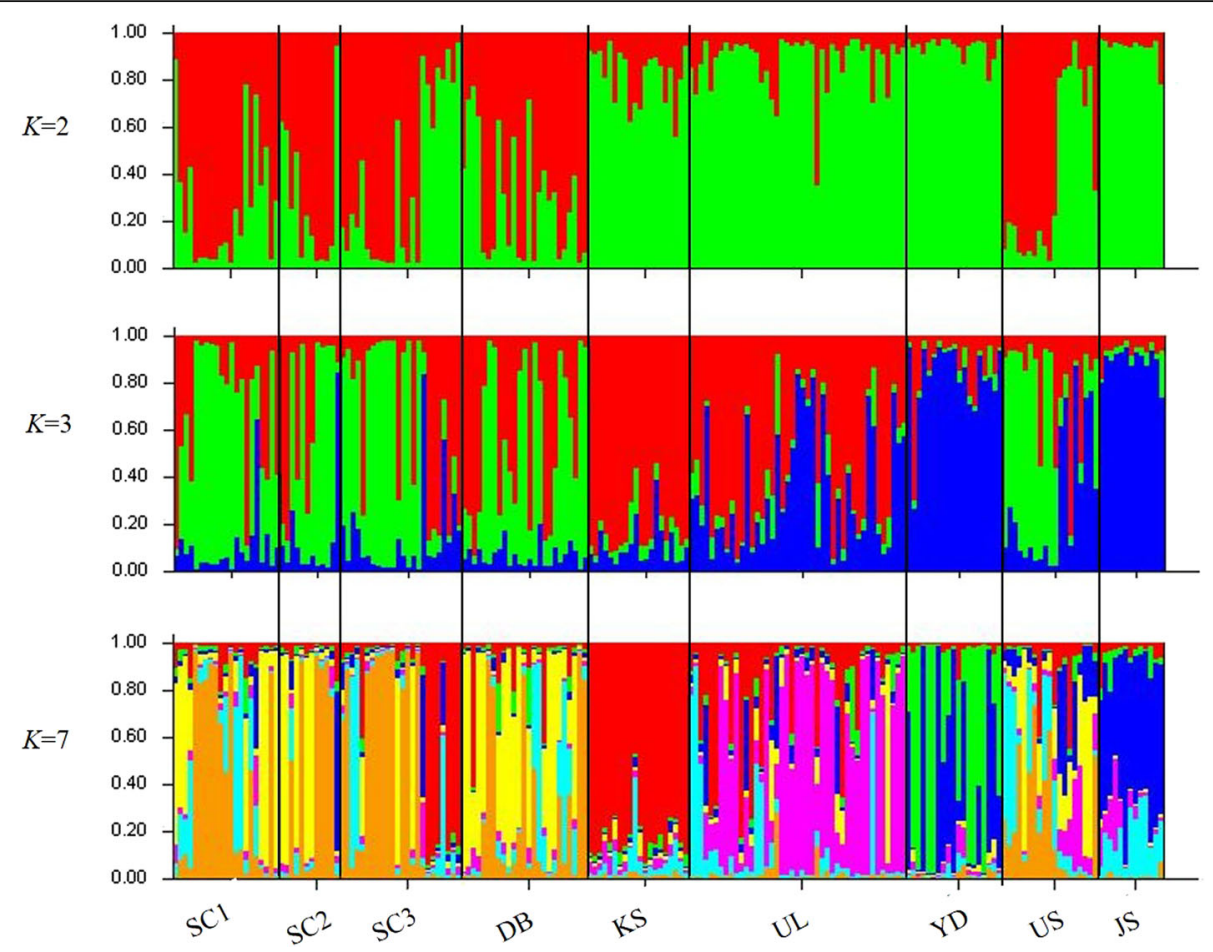

Fig. 4 Classification of individuals from nine populations of $J$. chinensis into several assumed clusters $(K=2,3,7)$ identified using the STRUCTURE program. Each population in the histogram represents the average proportions of cluster membership among the individuals sampled

disturbances such as construction of coastal highways, maintenance of banks, and development for touristic attractions.

The genetic differentiation of the $J$. chinensis populations was $11.5 \%$, and it was higher than $J$. phoenicea $\left(\Phi_{\mathrm{ST}}=0.106\right.$; Dzialuk et al. 2011) of the same genus. It showed a lower level than the dioecious plants, Taxus cuspidata ( $\Phi_{\mathrm{ST}}=0.200 ;$ Kwon and Kim 2002) and Ginkgo biloba $\left(G_{\mathrm{ST}}=0.161\right.$; Fan et al. 2004), the average of allogamous plants $\left(\Phi_{\mathrm{ST}}=0.27\right)$, and the average of gymnosperms $\left(\Phi_{\mathrm{ST}}=0.24\right.$; Nybom 2004). The estimated gene flow $(\mathrm{Nm}=2.05)$ in the $J$. chinensis populations did not influence the genetic drift (Wright 1931). The SC1, $\mathrm{SC} 2$, and SC3 populations that were distributed in the same region did not show much difference in the degree of differentiation among them. However, the KS, YD, and JS populations that grow in different geographical areas had a greater level of genetic differentiation compared with the rest of the eight populations, except with itself. J. chinensis populations are distributed in isolated state along the edges of the coastline rather than group. When a population grows on the outskirts of a distribution range in this manner, it may experience situations similar to habitat fragmentation depending on the degree of separation (Young et al. 1996). The fragmentation caused by the habitats destruction following land development greatly influences the gene flow (Manel et al. 2003); thus, the genetic differentiation among isolated populations occurs due to limitation of gene flow (Hutchison and Templeton 1999). Furthermore, genetic variation following gene flow is influenced by the degree of population size and the distance between populations (Eckert et al. 2008).

The analysis on genetic structure accurately reflects the result of the genetic differentiation of the nine J. chinensis populations assessed in this study (Fig. 4). In the cluster analysis, we confirmed that the KS and UL and YD and JS populations were separated into a single cluster when the virtual number of the cluster was $K=2$. The genetic diversity and geographical distribution of a population are influenced by the population size and the evolution of gene flow from the past to the present day (Vucetich and Waite 2003). Currently, the distribution of the J. chinensis populations demonstrates a tendency towards an isolated distribution in the restricted areas. However, Shin et al. (2015) estimated that this species used to have a continuous distribution centered in the East Sea areas considered the environmental and genetic factors. Genetic differentiation is greatly influenced by the fertilization modes of plants, cutoff of a gene flow due to a physical or physiological barrier, and decrease of the number of a population or of the number of individuals (Jacquemyn et al. 2004; Wang et al. 2008). The discontinued distribution trend of the domestic J. chinensis populations in Korea is thought to be influenced 
by artificial disturbance, succession, and suppression of vegetation, which has resulted in the fragmentation of a habitat and reduction of the number of individuals.

\section{Conclusion}

Isolated population ultimately poses a threat to the survival of species, and dioecious plants are particularly influenced by the sex ratio of its population in terms of evolution (Couvet et al. 1998; McCauley et al. 2000). The greatest influence on the maintenance of a population is the dispersion of pollen and the dispersal strategies of seeds (Olivieri et al. 1995; Ronce et al. 2000). The seeds of plants that belong to the genus Juniperus are mainly dispersed by birds, and it was clarified that $60 \%$ of them are dispersed more than $12 \mathrm{~m}$ (Adams 2011). However, most seeds of Juniperus have physiological dormancy (Mandel and Alberts 2005) and thus germination rate is low. The genetic diversity observed in this study was similar to that of other dioecious species (Phellodendron amurense S.I. $=0.421$, Lee et al. 2014; Fraxinus mandshurica S.I. $=0.509$, Cho et al. 2002), and degree of gene flow was not as low as dangerous level. Effective population size observed in the nine populations selected for this study was smaller than the actual population size. Particularly, KS population, which represented the lowest genetic diversity, showed higher percentage of female tree (Table 1). But the number of fruit-bearing individuals was small, and thus, it is expected that genetic fluctuation would be large in the future. Therefore, continued management of J. chinensis populations and rigorous conservation strategies such as in situ and ex situ conservation are required for the effective maintenance and conservation of the genetic diversity between and within the populations. Further, ecological network, which can help genetic exchange among KS, UL, YD, and JS populations, should be prepared to increase genetic diversity of J. chinensis, and investigation on minimum viable population (MVP) is also required to prevent local extinction.

\section{Funding}

This research was supported by Research Program through the Korea National Arboretum (KNA-2-5,08-5) funded by the Korea Forest Service.

\section{Availability of data and materials}

The datasets generated during and/or analyzed during the current study are available from the corresponding author on reasonable request.

\section{Authors' contributions}

CJM designed the study. KEH, JKS and SJK collected and analyzed the data. $\mathrm{KEH}$ and LCS wrote the initial draft of the manuscript. All authors read and approved the final manuscript.

Ethics approval and consent to participate

Not applicable.

Consent for publication

Not applicable.
Competing interests

The authors declare that they have no competing interests.

\section{Publisher's Note}

Springer Nature remains neutral with regard to jurisdictional claims in published maps and institutional affiliations.

\begin{abstract}
Author details
${ }^{1}$ Department of Biology, Seoul Women's University, Seoul 01797, Korea. ${ }^{2}$ Plant Management and Research Division, Seoul Botanic Park, Seoul 04520, Korea. ${ }^{3}$ Division of Forest Resource Conservation, Korea National Arboretum, Pocheon, Gyeonggi-do 11886, Korea. ${ }^{4}$ Baekdudaegan National Arboretum, Bonghwa-gun, Gyeongsangbuk-do 36209, Korea.
\end{abstract}

Received: 5 April 2018 Accepted: 20 June 2018

Published online: 09 July 2018

\section{References}

Adams, R. P. (2014). Junipers of the world: the genus Juniperus. Bloomington: Trafford Publishing.

Bell, G., \& Gonzalez, A. (2009). Evolutionary rescue can prevent extinction following environmental change. Ecology Letters, 12(9), 942-948.

Bohonak, A. J. (2002). IBD (isolation by distance): a program for analyses of isolation by distance. Journal of Heredity, 93(2), 153-154.

Cho K, Jeong J, Kim W, Kim Y, Hong Y. Genetic variation of populations of Fraxinus mandshurica Rupr. In Korea (Oleaceae) based on I - SSR Marker Analysis. Proceedings of Korean Forest Society. 2002. 114-115.

Choi, H. S., Hong, K. N., Chung, J. M., \& Kim, W. W. (2004). Spatial genetic structure and genetic diversity of a rare endemic Juniperus chinensis var. sargentii in Mt. Halla, Korea. The Korean Journal of Ecology., 27(5), 257-261.

Couvet, D., Ronce, O., \& Gliddon, C. (1998). The maintenance of nucleocytoplasmic polymorphism in a metapopulation: the case of gynodioecy. The American Naturalist., 152(1), 59-70.

Dzialuk, A., Mazur, M., Boratyńska, K., Montserrat, J. M., Romo, A., \& Boratyński, A. (2011). Population genetic structure of Juniperus phoenicea (Cupressaceae) in the western Mediterranean Basin: gradient of diversity on a broad geographical scale. Annals of Forest Science., 68(8), 1341-1350.

Eckert, C. G., Samis, K. E., \& Lougheed, S. C. (2008). Genetic variation across species' geographical ranges: the central-marginal hypothesis and beyond. Molecular ecology., 17(5), 1170-1188.

Evanno, G., Regnaut, S., \& Goudet, J. (2005). Detecting the number of clusters of individuals using the software STRUCTURE: a simulation study. Molecular ecology., 14(8), 2611-2620.

Excoffier, L., Laval, G., \& Schneider, S. (2005). Arlequin (version 3.0): an integrated software package for population genetics data analysis. Evolutionary Bioinformatics. 1, 117693430500100003.

Falush, D., Stephens, M., \& Pritchard, J. K. (2003). Inference of population structure using multilocus genotype data: linked loci and correlated allele frequencies. Genetics, 164(4), 1567-1587.

Falush, D., Stephens, M., \& Pritchard, J. K. (2007). Inference of population structure using multilocus genotype data: dominant markers and null alleles. Molecular ecology notes., 7(4), 574-578.

Fan, X. X., Shen, L., Zhang, X., Chen, X. Y., \& Fu, C. X. (2004). Assessing genetic diversity of Ginkgo biloba L. (Ginkgoaceae) populations from China by RAPD markers. Biochemical genetics, 42(7-8), 269-278.

Farjon, A. (2008). The natural history of conifers Portland: Timber Press.

Frankham, R. (2015). Genetic rescue of small inbred populations: meta-analysis reveals large and consistent benefits of gene flow. Molecular Ecology., 24(11), 2610-2618.

Gonzalez A, Mouquet N, \& Loreau M. (2009). Biodiversity as spatial insurance: the effects of habitat fragmentation and dispersal on ecosystem functioning. In: Naeem S, Bunker DE, Hector A, Loreau M, Perrings C, Eds. Biodiversity, ecosystem functioning, and human wellbeing. New York: Oxford University Press, 134-46.

Hamrick, J. L., \& Godt, M. J. W. (1990). Allozyme diversity in plant species. Plant population genetics, breeding, and genetic. Resources, 43-63.

Hamrick, J. L., \& Godt, M. J. W. (1996). Effects of life history traits on genetic diversity in plant species. Philosophical Transactions of the Royal Society B: Biological Sciences., 351(1345), 1291-1298.

Hartl, D. L., \& Clark, A. G. (1997). Principles of population genetics (vol. 116). Sunderland: Sinauer associates. 
Hou, Y., \& Lou, A. (2011). Population genetic diversity and structure of a naturally isolated plant species, Rhodiola dumulosa (Crassulaceae). PLoS One, 6(9), e24497.

Hughes, A. R., Inouye, B. D., Johnson, M. T., Underwood, N., \& Vellend, M. (2008). Ecological consequences of genetic diversity. Ecology Letters, 11(6), 609-623.

Hutchison, D. W., \& Templeton, A. R. (1999). Correlation of pairwise genetic and geographic distance measures: inferring the relative influences of gene flow and drift on the distribution of genetic variability. Evolution, 53(6), 1898-1914.

IUCN. The IUCN red list of threatened species, Conifer Specialist Group Ver. 2.3. 1998.

Jacquemyn, H., Honnay, O., Galbusera, P., \& Roldán-Ruiz, I. (2004). Genetic structure of the forest herb Primula elatior in a changing landscape. Molecular Ecology., 13(1), 211-219.

Jeong, J. H., Kim, E. H., Guo, W., Yoo, K. O., Jo, D. G., \& Kim, Z. S. (2010). Genetic diversity and structure of the endangered species Megaleranthis saniculifolia in Korea as revealed by allozyme and ISSR markers. Plant systematics and evolution., 289(1-2), 67-76

Jo, H. J. (2012). Antitumor efficacy evaluation for cedrol dosage form studies. Department of life science and biotechology, Graduate school, Dong-Eui University. Master's thesis in Korea.

Kwon, H. Y., \& Kim, Z. S. (2002). I-SSR variation within and among Korean populations in Taxus cuspidata. Journal Korean forestry society., 91(5), 654-660.

Lee, J. H. (2005). Ecological approach for the effective conservation and management of forest vegetation in Ulleung island, Korea. Graduate school, Kyungpook National University. Doctoral thesis in Korea.

Lee, J. W., Hong, K. N., \& Kang, J. T. (2014). Genetic diversity and genetic structure of Phellodendron amurense populations in South Korea. Journal of Korean Forest Society., 103(1), 51-58.

Legendre, P., \& Legendre, L. (1998). Numerical ecology: second English edition. Developments in environmental modelling, 20.

Lewis, D. (1942). The evolution of sex in flowering plants. Biological Reviews, 17(1), 46-67.

Lienert, J., \& Fischer, M. (2003). Habitat fragmentation affects the common wetland specialist Primula farinosa in north-east Switzerland. Journal of Ecology, 91(4), 587-599.

Llorens, T. M., Ayre, D. J., \& Whelan, R. J. (2004). Evidence for ancient genetic subdivision among recently fragmented populations of the endangered shrub Grevillea caleyi (Proteaceae). Heredity, 92(6), 519-526.

Mandel, R., \& Alberts, D. (2005). Propagation protocol for Oneseed and Utah junipers (Juniperus monosperma and Juniperus osteosperma). Native Plants Journal., 6(3), 263-266.

Manel, S., Schwartz, M. K., Luikart, G., \& Taberlet, P. (2003). Landscape genetics: combining landscape ecology and population genetics. Trends in ecology \& evolution., 18(4), 189-197.

McCauley, D. E., Olson, M. S., Emery, S. N., \& Taylor, D. R. (2000). Population structure influences sex ratio evolution in a gynodioecious plant. The American Naturalist., 155(6), 814-819.

McDermott, J. M., \& McDonald, B. A. (1993). Gene flow in plant pathosystems. Annual Review of Phytopathology, 31(1), 353-373.

Meloni, M., Perini, D., Filigheddu, R., \& Binelli, G. (2006). Genetic variation in five Mediterranean populations of Juniperus phoenicea as revealed by inter-simple sequence repeat (ISSR) markers. Annals of Botany., 97(2), 299-304.

Murphy, W. D. (1990). Assessment and modification of cognitive distortions in sex offenders. In Handbook of sexual assault. Boston: Springer, 331-342.

Nei, M. (1973). Analysis of gene diversity in subdivided populations. Proceedings of the National Academy of Sciences., 70(12), 3321-3323.

Nei, M. (1978). Estimation of average heterozygosity and genetic distance from a small number of individuals. Genetics, 89(3), 583-590.

Nybom, H. (2004). Comparison of different nuclear DNA markers for estimating intraspecific genetic diversity in plants. Molecular ecology., 13(5), 1143-1155.

Olivieri, I., Michalakis, Y., \& Gouyon, P. H. (1995). Metapopulation genetics and the evolution of dispersal. The American Naturalist., 146(2), 202-228.

Rockman, M. V. (2012). The QTN program and the alleles that matter for evolution: all that's gold does not glitter. Evolution, 66(1), 1-17.

Ronce, O., Perret, F., \& Olivieri, I. (2000). Evolutionarily stable dispersal rates do not always increase with local extinction rates. The American Naturalist., 155(4), 485-496.

Shannon, C. E., \& Weaver, W. (1949). The mathematical theory of communication. Urbana: University of Illinois Press.

Shin, J. K., Chung, J. M., Kim, J. S., Yoon, C. W., \& Shin, C. H. (2015). The distribution and dynamics between sexes, conservation of natural populations of a rare woody plant, Juniperus chinensis L. Korean Journal of Plant Resources., 28(4), 400-410.

Terrab, A., Schönswetter, P., Talavera, S., Vela, E., \& Stuessy, T. F. (2008). Rangewide phylogeography of Juniperus thurifera $\mathrm{L}$., a presumptive keystone species of western Mediterranean vegetation during cold stages of the Pleistocene. Molecular Phylogenetics and Evolution., 48(1), 94-102.

Thomson, J. D., \& Barrett, S. C. (1981). Temporal variation of gender in Aralia hispida Vent.(Araliaceae). Evolution, 35(6), 1094-1107.

Ulleung County The Office Ulleung County history book. 2007.

Vucetich, J. A., \& Waite, T. A. (2003). Spatial patterns of demography and genetic processes across the species' range: null hypotheses for landscape conservation genetics. Conservation genetics., 4(5), 639-645.

Wang, J., Ye, Q., Kang, M., \& Huang, H. (2008). Novel polymorphic microsatellite loci and patterns of pollen-mediated gene flow in an ex situ population of Eurycorymbus cavaleriei (Sapindaceae) as revealed by categorical paternity analysis. Conservation Genetics., 9(3), 559-567.

Wright, S. (1931). Evolution in Mendelian populations. Genetics, 16(2), 97-159.

Yeh, F. C., Yang, R. C., \& Boyle, T. (1999). POPGENE version1. 32, Microsoft window-base software for population genetic analysis: a quick user's guide. University of Alberta. Center for International Forestry Research, Alberta.

Young, A., Boyle, T., \& Brown, T. (1996). The population genetic consequences of habitat fragmentation for plants. Trends in Ecology \& Evolution., 11(10), 413-418.

\section{Ready to submit your research? Choose BMC and benefit from:}

- fast, convenient online submission

- thorough peer review by experienced researchers in your field

- rapid publication on acceptance

- support for research data, including large and complex data types

- gold Open Access which fosters wider collaboration and increased citations

- maximum visibility for your research: over $100 \mathrm{M}$ website views per year

At BMC, research is always in progress.

Learn more biomedcentral.com/submissions 